\title{
Coherent Microburst Electron Precipitation Measured from a Satellite
}

\author{
G.H. NaKano, W.L. Imhof, and J.B. Reagan \\ Lockheed Palo Alto Research Laboratory, Palo Alto, \\ California 94304, U.S.A.
}

(Received February 7, 1978)

To date direct satellite measurements of precipitating microburst electrons have been extremely sparse (O'Brien, 1964; OLIVEN et al., 1968) and with the exception of some rocket data (LAMPTON, 1967), both angular distributions and differential energy spectra have not been available heretofore. Here we wish to report angular distributions and energy spectra of microburst electrons acquired with an array of solid state detectors and scintillation spectrometers carried on board a low altitude $(770-805 \mathrm{~km})$ attitude controlled, polar-orbiting satellite, 1971-089A. Two adjoining trains of highly modulated precipitating electrons were observed at $L=4.3$ during a geomagnetically disturbed period $\left(K_{\mathrm{p}}=8+\right)$ on 5 August $1972(52520 \mathrm{sec}$ UT) in the recovery phase of the great solar particle event of the previous day.

The temporal features of the counting rates, shown in Fig. 1, are similar to the well known X-ray microbursts observed at higher $L$-values with high altitude balloons, i.e., ANDERSON (1965). The upper three panels show the counting rates from the silicon detectors viewing different zenith angles as indicated. The lower panel depicts the counting rates from a scintillation counter at $90^{\circ}$. Within each of the trains, made up of about 6 micropeaks, the spikes of energetic electrons recur with precise periods of $0.35 \mathrm{sec}$ and $0.38 \mathrm{sec}$, respectively. The angular distributions of the electron peaks in the two trains are markedly different. In the first train the micropeaks are generally isotropic and highly bunched with peak widths of about $32 \mathrm{msec}$ (FWHM). These features are indicative of the detection of freshly scattered electrons. The second train exhibits an angular distribution of quasi-trapped particles, peaked at $90^{\circ}$ pitch angle, and with no discernible peaks seen by the HEADI 2 detector which at the time was pointed at a pitch angle of $43^{\circ}$. The widths of the peaks in the quasi-trapped distribution are significantly broader, about $90 \mathrm{msec}$. Although the peak widths and recurrence periods are considerably shorter than those typical of X-ray microbursts measured during less active times, and at somewhat higher latitudes, these observations are in good agreement with the balloon measurements of Brown (1973) acquired during the same time period at $L=5.5$.

A more detailed analysis of these data indicates the possibility that both trains of micropeaks may have resulted from the same or a related interaction. Both the timing and the difference in the angular distributions of the two overlapping trains of micropeaks suggest that the precipitation occurred nearly simultaneously but the 


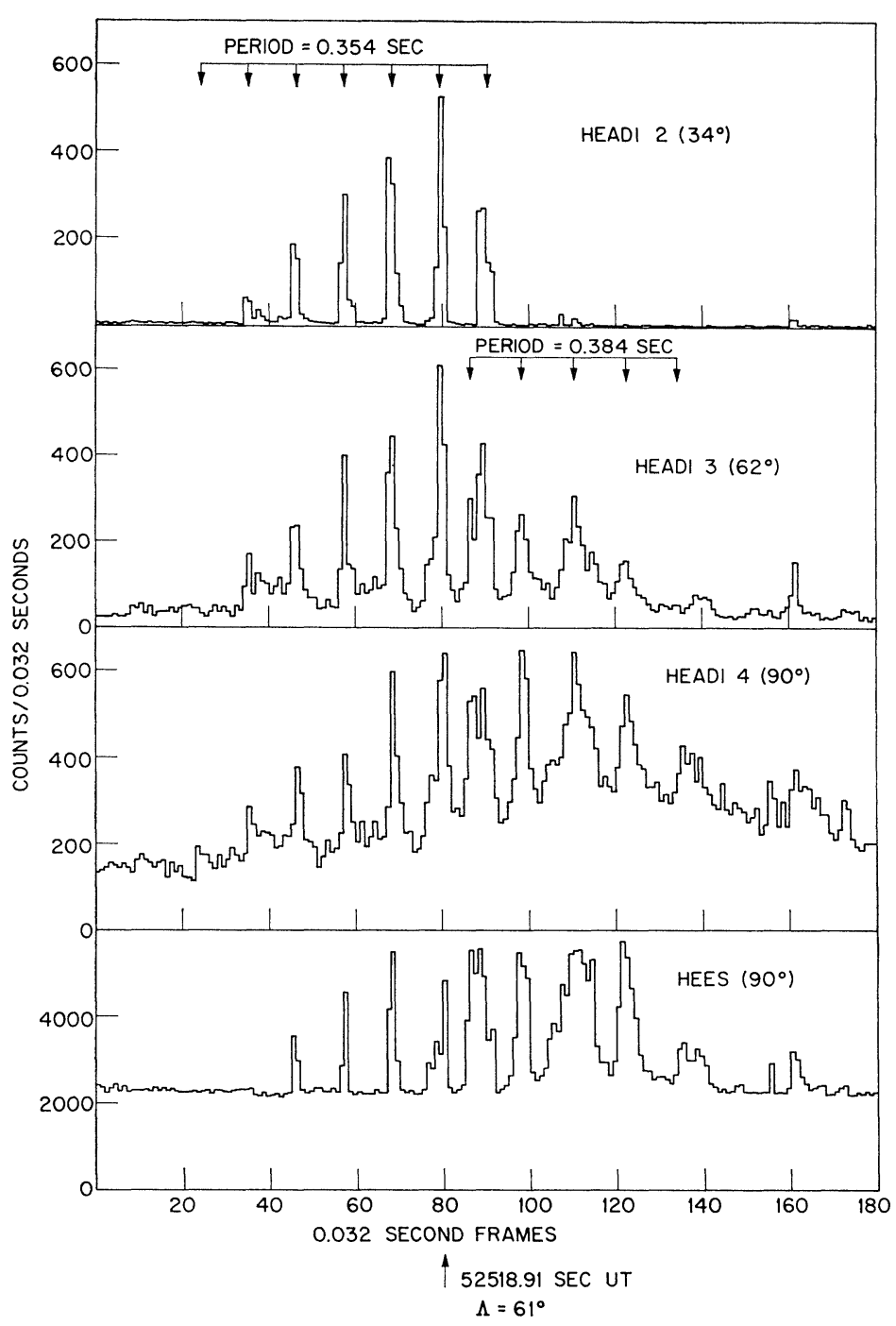

Fig. 1. Temporal profile of two overlapping trains of microburst electrons detected at $790 \mathrm{~km}$ altitude on 5 August 1972.

latter train of electrons mirrored slightly to the west of the spacecraft trajectory and those electrons which were not absorbed by the atmosphere and mirrored at or below the satellite altitude were recorded by our detectors after the first bounce. A preliminary analysis of the spectral data above $130 \mathrm{keV}$ was performed and the electron energy spectra averaged over the peaks and in the valleys were fitted to exponential functions with e-folds of $119 \mathrm{keV}$ and $162 \mathrm{keV}$, respectively.

This work was supported by the Defense Nuclear Agency through the Office of Naval Research (Contract N00014-70-C-0203) and the Lockheed Independent Research Program. 


\section{REFERENCES}

Anderson, K.A., Auroral Phenomena, edited by M. Walt, 46 pp., Stanford Univ. Press, Stanford, California, 1965.

BRown, R.R., Observations of narrow microburst trains in the geomagnetic storm of August 4-6, 1972, J. Geophys. Res., 78, 1727-1729, 1973.

LAmpton, M., Daytime observations of energetic auroral-zone electrons, J. Geophys. Res., 72, 58175823, 1967.

O'BRIEN, B.J., High-latitude geophysical studies with satellite Injuns 3, 3: Precipitation of electrons into the atmosphere, J. Geophys. Res., 69, 13-43, 1964.

Oliven, M.N., D. Venkantesan, and K.G. McCracken, Microburst phenomena, 2. Auroral zone electrons, J. Geophys. Res., 73, 2345-2353, 1968. 